\title{
BMJ Open Quality Contribution of adverse events to death of hospitalised patients
}

\author{
Ellinor Christin Haukland, ${ }^{1,2}$ Kjersti Mevik ${ }^{2,3}$ Christian von Plessen, ${ }^{4,5}$ \\ Carsten Nieder, ${ }^{1,6}$ Barthold Vonen ${ }^{2,7}$
}

To cite: Haukland EC, Mevik K, von Plessen C, et al. Contribution of adverse events to death of hospitalised patients. BMJ Open Quality 2019;8:e000377. doi:10.1136/ bmjoq-2018-000377

Received 9 March 2018 Revised 22 November 2018 Accepted 11 December 2018

A) Check for updates

(C) Author(s) (or their employer(s)) 2019. Re-use permitted under CC BY-NC. No commercial re-use. See rights and permissions. Published by BMJ.

${ }^{1}$ Department of Oncology and Palliative Medicine, Nordland Hospital Trust, Bodø, Norway ${ }^{2}$ Department of Community Medicine, University of Troms $\emptyset$ Tromsø, Norway

${ }^{3}$ Department of General Surgery, Nordland Hospital Trust, Bodø

Norway

${ }^{4}$ Centre of Quality, Region of Southern Denmark, Middelfart, Denmark

${ }^{5}$ Faculty of Health Sciences, Institute for Regional Health Research, University of Southern Denmark, Odense, Denmark

${ }^{6}$ Department of Clinical

Medicine, University of Tromsø, Tromsø, Norway

${ }^{7}$ Centre for Clinical

Documentation and Evaluation, Northern Norway Regional Health Authority, Troms $\emptyset$, Norway

Correspondence to Dr Ellinor Christin Haukland; ellinor.haukland@nlsh.no

\begin{abstract}
Background There is no standardised method to investigate death as a patient safety indicator and we need valid and reliable measurements to use adverse events contributing to death as a quality measure.

Objective To investigate the contribution of severe adverse events to death in hospitalised patients and clarify methodological differences using the Global Trigger Tool method on all inpatient deaths compared with a sample of general hospitalised patients.
\end{abstract}

Method Retrospective records reviewing using the Global Trigger Tool method.

Results In $0.3 \%$ of hospital admissions, adverse events contribute to inpatient death. Patients who die in hospital have twice the rate of adverse events per 1000 patient days compared with general patients, 76.7 vs 36.5 ( $p<0.001, \mathrm{RR} 2.10,95 \% \mathrm{Cl} 1.79$ to 2.47 ). Patients dying in hospital experience seven times the rate of severe adverse events, $38.4 \%$ vs $5.2 \%$ ( $p<0.001$, RR $2.10,95 \%$ Cl 1.79 to 2.47). For 86 out of 377 inpatient deaths, the adverse event is so severe that it contributes to death. $27.9 \%$ of severe adverse events contributing to death originate in primary care. Lower respiratory infections $(p<0.001, R R$ $2.81,95 \% \mathrm{Cl} 1.76$ to 4.51$)$, medication harm $(\mathrm{p}<0.001, \mathrm{RR}$ $5.21,95 \% \mathrm{Cl} 3.04$ to 8.94 ) and pressure ulcers ( $p=0.04$, RR $2.23,95 \% \mathrm{Cl} 1.03$ to 4.85 ) are significantly more frequent for inpatient deaths than in the general sample of hospital patients.

Conclusions Patients dying in hospitals experience seven times the rate of severe adverse events. Reviewing all inpatient death by the Global Trigger Tool method discloses new valid and reliable data of severe adverse events contributing to death which otherwise would be undetected.

\section{INTRODUCTION}

It has been estimated that adverse events due to medical error are the third leading cause of death in the USA. ${ }^{12}$ These estimates are based on studies of general hospitalised populations extrapolating that $0.6 \%-1.1 \%$ of admissions result in death due to adverse events. ${ }^{34}$ Other studies of inpatient deaths indicate that most types of adverse events occur more often in patients dying in hospitals. ${ }^{56}$ This makes studying inpatient death in an efficient way to identify preventable adverse events and provide valuable information in areas for improvement. ${ }^{6}$ A number of studies investigating mortality have found that only $0.5 \%-6.0 \%$ of adverse events contributing to death are preventable..$^{7-10}$ However, preventability is often difficult to determine and including this subjective judgement to mortality measures makes the measure even more uncertain. ${ }^{11}$ There is no standardised method of investigating death as a patient safety indicator, and uncertainty about the results has lead to an ongoing discussion about using estimated mortality from adverse events as a quality measure in patient safety. ${ }^{12} 13$ All the methods used have limitations such as extrapolation of results from samples, data not being based on a representative population or include subjective judgement of expectancy of death or preventability of adverse events. Despite these epidemiological controversies, death is the most severe consequence of an adverse event, and knowing the actual occurrence and type of adverse events contributing to death can be valuable to improve patient safety.

Retrospective record reviewing with trigger tools is a widely used methodology for a systematic review of adverse events in patient records, with high sensitivity and specificity compared with other methods. ${ }^{414}$ Most trigger tool analyses are performed on samples of general hospitalised patients that involve few deaths and may therefore not provide valid epidemiological estimates of all patients dying in hospitals. Similar studies conducted on inpatient deaths are mainly based on samples and include judgement of preventability in assessing adverse events contributing to death. ${ }^{6-10}$ Instead of collecting data on many less severe adverse events that rarely result in death, an in-depth analysis of all hospital deaths could provide more valid and reliable data on severe adverse events that otherwise are undetected.

The aim of our study is to investigate the contribution of severe adverse events to death in hospitalised patients and clarify methodological differences using the Global Trigger Tool (GTT) method on all inpatient deaths compared with a sample of general hospitalised patients. 


\section{METHOD}

\section{Study design}

The study is a retrospective record review using the GTT method to compare adverse events in a sample of general hospitalised patients to review all inpatient deaths from 1 January 2013 to 31 December 2013.

\section{Setting}

The study was performed at Nordland Hospital Trust in Norway. This is a public health trust consisting of three hospitals: one central and two smaller district general hospitals, with 524 beds in total. The three hospitals cover a population of approximately 136000 people and offer most surgical and medical specialties.

\section{Study population}

The sample of general hospitalised patients includes 1680 patient records. Ten patient records were randomly sampled twice monthly through block randomisation from the discharge list of seven functional units in the trust (surgery, orthopaedics, internal medicine, gynaecology/obstetrics, neurology/others and the district hospitals of Lofoten and Vesterålen). Patients under the age of 18 , patients with a length of stay $<24$ hours or patients admitted primarily for psychiatric conditions or rehabilitation were excluded.

For the inpatient death sample, all 377 patients who died in the three hospitals during 2013 were included. Five patients under the age of 18 were excluded (figure 1).

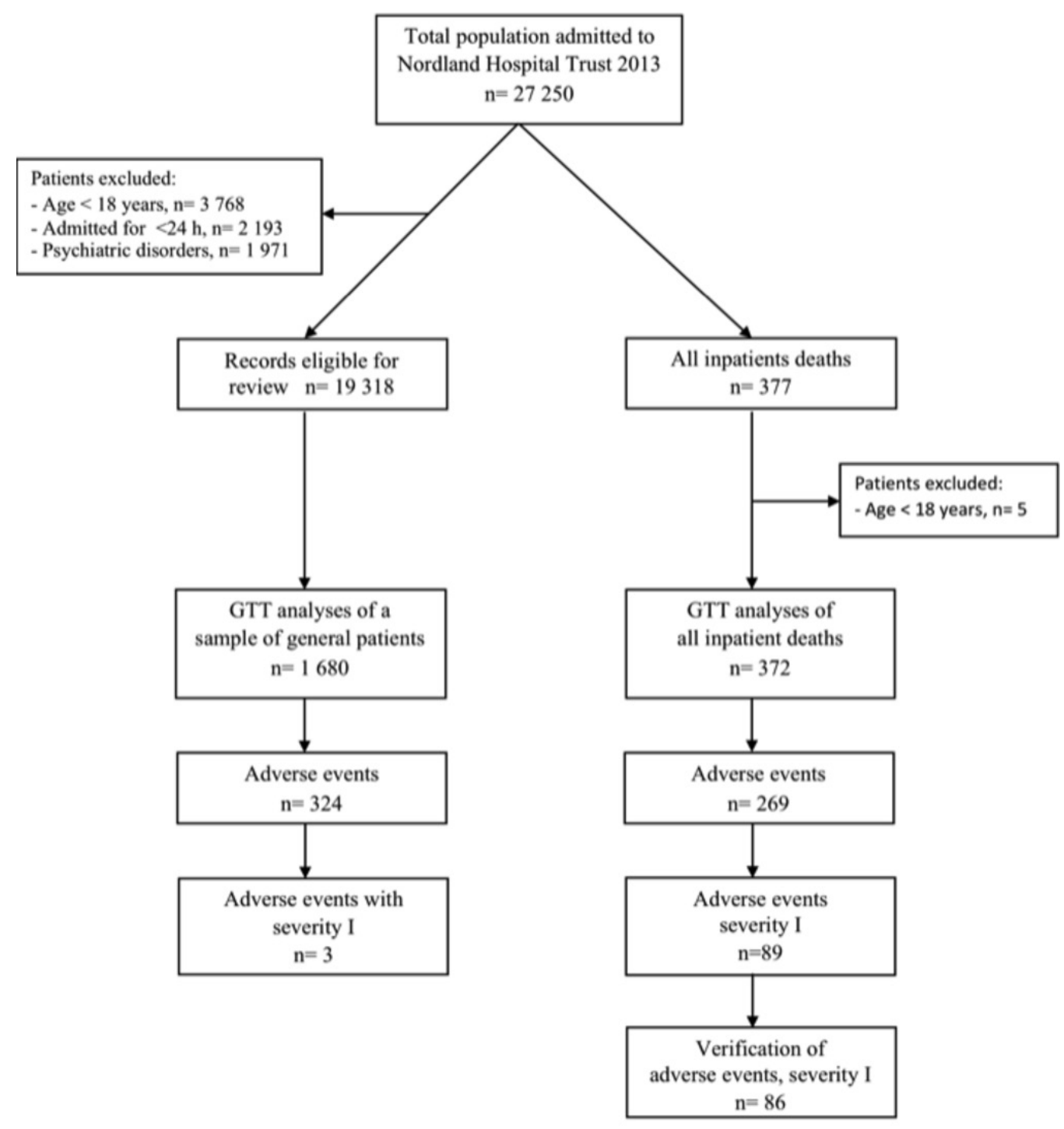

Number, distribution of severity and type of adverse events compared between the samples.

Figure 1 Study population and design. GTT, Global Trigger Tool. 


\section{GTT review of a general sample}

Nordland hospital trust since 2010 has routinely performed GTT reviews of general hospitalised patients. Our general sample consist of 1680 patient records routinely reviewed in 2013. Seven different teams performed a two-stage review according to the Norwegian version of The Institute of Healthcare Improvement GTT manual. ${ }^{15} 16$ Two nurses reviewed all records independently before they together reached consensus on presence, category and severity of adverse events. A physician then verified their findings.

\section{GTT review of inpatient deaths}

During 6 months in 2015, an independent team of two nurses and one physician reviewed the records of all hospital deaths during 2013. The review was done in the same way as the general sample, but the physician reached consensus together with the nurses. Then, two other physicians independently re-reviewed the records of adverse events contributing to death and agreed/disagreed on the adverse event, severity and type of harm. Finally, the physician from the primary review team and the verifying physicians discussed the findings and reached consensus.

\section{Definition and classification of adverse events}

Adverse events were defined as: 'Unintended physical injury resulting from or contributed to by medical care that requires additional monitoring, treatment or hospitalisation, or that results in death. ${ }^{16}$ The severity of adverse events was categorised according to the National Coordinating Council for Medication Error Reporting and Prevention Index (NCC MERP index), ${ }^{17}$ :

- Category E: temporary harm that required intervention.

- Category F: temporary harm that required initial or prolonged hospitalisation.

- Category G: permanent patient harm.

- Category H: intervention required necessary to sustain life.

- Category I: harm contributes to patient death.

Adverse events were categorised into 23 categories according to recommendations of the Norwegian GTT manual. ${ }^{15}$ For statistical purpose, the categories were aggregated into eight main categories in the study: hospital-acquired infections, surgical complications, bleeding/ thrombosis, patient fall/fracture, medication harm, obstetric harm, pressure ulcer and others. Table 1 gives an overview of the original categories and their aggregation. Adverse events associated with medical care given prior to or during hospitalisation were included to evaluate the total number of adverse events. For medication-related adverse events, the generic name was obtained. In addition, we obtained age, gender, length of stay, hospital, department, type of admission, primary and secondary diagnosis on discharge classified according to International Statistical Classification of Diseases and Related Health Problems 10th Revision (ICD-10) system.

\section{Statistical analysis}

Demographic variables were compared using the Pearson's $\mathrm{X}^{2}$ test and the Mann-Whitney U test. Incidence rates of adverse events, severities and categories of adverse events were compared using Poisson regression in generalised linear models. Rates were calculated as adverse events per 1000 patient days and as the percentage of admissions with one or more adverse events. Log patient days were used as an offset variable to compare rates per 1000 patient days, and for admissions with adverse events, the offset variable was set to a fixed value of 0 . In addition, we adjusted for the demographic variables such as age, gender, length of stay, hospital, department, type of admission and primary diagnosis. A $p$ value $<0.05$ was deemed statistically significant. Data were analysed with IBM SPSS V.24.0.0.2.

\section{RESULTS}

\section{Demographic characteristics}

Patients dying in the hospital are on average older than 18.7 years, stay 5.2 days longer, are mainly emergency admissions and die more frequently in departments of internal medicine compared with patients discharged alive from hospital. Their three most common primary diagnoses are circulatory disorders, respiratory disorders and cancer (table 2).

\section{Comparison of adverse events}

Analysing all inpatient deaths, adverse events contributed to death in $0.3 \%$ of all hospital admissions. Forty-six per cent of admissions for inpatient death experience one or more adverse events, compared with $16.3 \%$ of admissions in the general sample $(\mathrm{p}<0.001$, RR $2.83,95 \%$ CI 2.34 to 3.43). Inpatient deaths have twice the rate of adverse events per 1000 patient days compared with the general sample, 76.7 vs 36.5 ( $\mathrm{p}<0.001$, RR $2.10,95 \%$ CI 1.79 to 2.47). Adjusting for demographic variables did not alter the result regarding the rate of adverse events per 1000 patient days, 6.1 vs 3.1 ( $\mathrm{p}<0.001$, RR $1.94,95 \%$ CI 1.58 to 2.39).

\section{Severity of adverse events}

More severe adverse events (severity G, H and I) were identified for inpatient deaths than in the general sample, $38.4 \%$ vs $5.2 \%$. Adjusted for demographic variables, admissions with adverse events and rates of adverse events per 1000 patient days for inpatient deaths are significantly higher for severe adverse events (severity G, H and I) ( $\mathrm{p}<0.001$, RR 24.0, 95\% CI 11.47 to 50.13). There is no significant difference between the samples in rates of temporary adverse events (severity $\mathrm{E}$ and $\mathrm{F}$ ) per 1000 patient days $(\mathrm{p}=0.138$, RR $1.19,95 \%$ CI 0.95 to 1.50) (table 3). For inpatient deaths, 89 adverse events were primarily categorised as severity I. After verification and consensus, two adverse events were dismissed, one changed severity and two changed types of harm, concluding with 86 adverse events contributed to death 
Table 2 Characteristics of patients

\begin{tabular}{|c|c|c|}
\hline Parameter & $\begin{array}{l}\text { General } \\
\text { patients } \\
n=1680\end{array}$ & $\begin{array}{l}\text { Inpatient } \\
\text { deaths } \\
\mathrm{n}=372\end{array}$ \\
\hline Mean age, years (SD) & $58.8(21.3)$ & $77.5(13.2)^{\star}$ \\
\hline $18-102$ & $18-102$ & $18-102$ \\
\hline Mean length of stay, days (SD) $)^{*}$ & $5.3(5.9)$ & $9.4(11.7)^{\star}$ \\
\hline $1-86$ & $1-86$ & $1-65$ \\
\hline \multicolumn{3}{|l|}{ Gender, N (\%) ${ }^{*}$} \\
\hline Female & $993(59.1)$ & $182(44.9)$ \\
\hline Male & $687(40.9)$ & $190(51.1)$ \\
\hline \multicolumn{3}{|l|}{ Type admission, $\mathrm{N}(\%)^{*}$} \\
\hline Acute & $1211(72.1)$ & $364(97.8)$ \\
\hline Planned & 469 (27.9) & $8(2.2)$ \\
\hline \multicolumn{3}{|l|}{ Hospital, N (\%)* } \\
\hline District Hospital Lofoten & $240(14.3)$ & $56(15.6)$ \\
\hline District Hospital Vesterålen & $240(14.3)$ & $87(23.4)$ \\
\hline Central Hospital Bodø & $1200(71.4)$ & $227(61.0)$ \\
\hline \multicolumn{3}{|l|}{ Department, N (\%) ${ }^{\star}$} \\
\hline Internal medicine & $486(28.9)$ & $258(69.4)$ \\
\hline Surgery & $680(40.5)$ & $93(25.0)$ \\
\hline Neurology & $151(9.0)$ & $17(4.6)$ \\
\hline Gynaecology & $276(16.4)$ & 0 \\
\hline Other departments & $87(5.2)$ & $3(0.8)$ \\
\hline \multicolumn{3}{|l|}{ Primary diagnosis, $\mathrm{N}(\%)^{*}$} \\
\hline Infections & $28(1.7)$ & $23(6.2)$ \\
\hline Cancer & $112(6.7)$ & $78(21.0)$ \\
\hline Endocrine and haematological & $86(5.1)$ & $6(1.6)$ \\
\hline Neurological disorders & $69(4.1)$ & $4(1.1)$ \\
\hline Circulatory disorders & $164(9.8)$ & $102(27.4)$ \\
\hline Respiratory disorders & $127(7.6)$ & $93(25)$ \\
\hline Gastrointestinal disorders & $144(8.6)$ & $25(6.7)$ \\
\hline $\begin{array}{l}\text { Skeletal and muscular } \\
\text { disorders }\end{array}$ & $21(1,3)$ & $3(0.8)$ \\
\hline Urinary disorders & $150(8.9)$ & $16(4.3)$ \\
\hline Pregnancy and birth & $231(13.8)$ & 0 \\
\hline Damage and poisoning & $170(10.1)$ & $16(4.3)$ \\
\hline Unspecific symptoms & $114(6.8)$ & $4(1.1)$ \\
\hline Other disorders & $264(15.7)$ & $18(4.8)$ \\
\hline \multicolumn{3}{|l|}{ Origin of adverse events, $N(\%)^{\star}$} \\
\hline Primary care & $43(11.6)$ & $51(19.0)$ \\
\hline Hospital & $329(88.4)$ & $218(81.0)$ \\
\hline
\end{tabular}

*Differences between groups for all characteristics, $p<0.0001$.

for inpatient deaths compared with three adverse events in the general sample.

\section{Origin of adverse events}

Nineteen per cent of adverse events originated in primary care for inpatient deaths compared with $11.6 \%$ in the
Table 3 Distribution of adverse events by severity

\begin{tabular}{llllll}
\hline \multirow{2}{*}{$\begin{array}{l}\text { Adverse } \\
\text { events }\end{array}$} & \multicolumn{4}{l}{ Severity categories } \\
\cline { 2 - 6 } & $\mathbf{E}$ & $\mathbf{F}$ & $\mathbf{G}^{*}$ & $\mathbf{H}^{*}$ & $\mathbf{I}^{*}$ \\
\hline $\begin{array}{l}\text { General } \\
\text { patients } \\
\mathrm{n}=324\end{array}$ & $174(53.7)$ & $133(41.0)$ & $12(3.7)$ & $2(0.6)$ & $3(0.9)$ \\
$\begin{array}{l}\text { Inpatient } \\
\text { deaths } \\
\mathrm{n}=269\end{array}$ & $90(33.4)$ & $76(28.3)$ & $12(4.5)$ & $5(1.9)$ & $86(32.0)$ \\
& & & & & \\
\end{tabular}

*Estimated differences per 1000 patient days using Poisson regression adjusted for demographic variables, $p<0.001$. Severity categories according to the NCC MERP index.

general sample. For inpatient deaths, $27.9 \%$ of adverse events contributing to death were present on admission and originated in primary care. Inpatient deaths where the adverse event originate in primary care has a shorter length of stay (6.9 vs 15.8 days) and patients are on average 6.7 years older ( 84.4 vs 77.7 years) compared with inpatient deaths where adverse events originate after admission to hospital.

\section{Type of adverse events}

For inpatient death, we identify more healthcare-associated infections than in the general sample, $42.4 \%$ vs $33.0 \%$. These are mainly lower respiratory infections, $25.5 \%$ vs $10.5 \%$. Inpatient deaths have more than five times the risk rate for adverse events related to medications than the general sample, $28.0 \%$ vs $8.3 \%$, and twice the risk rate of developing pressure ulcers, $9.2 \%$ vs $3.4 \%$ (table 1).

\section{Type of adverse events contributing to death}

Lower respiratory infections with $47.7 \%$ and medication adverse events with $19.8 \%$ are the most common types of adverse events contributing to death among the 86 inpatient deaths. Patients dying of lower respiratory infections are on average 82 years old and stay in hospital on average 16.9 days. Patients acquiring the lower respiratory infection in primary care have a significantly shorter length of stay than those with a hospital-acquired infection, 6.0 vs 22.5 days. Medication adverse events contribute to death for 17 of the inpatient deaths. Twelve of these patients have cancer as a primary or secondary diagnosis, whereof 8 patients experience lethal complications after chemotherapy (table 1).

\section{DISCUSSION}

Patients dying in hospitals differ from general hospitalised patients in several ways and experience seven times the rate of severe adverse events. GTT review of all inpatient deaths and a sample of general hospitalised patients disclose different measures and perspectives that need to be considered using adverse events contributing to death as a valid and reliable quality measure.

The high ratio of adverse events for inpatient deaths in our study is similar to reviews of inpatient deaths done 
in the Netherlands and a mortality review programme at Mayo Clinic in the USA. ${ }^{56}$ Nevertheless, our rates are higher than most other studies undertaken on general hospitalised patients. ${ }^{18-20}$ Even though we have a higher rate of adverse events contributing to death than other studies, adverse events contributing to inpatient deaths only account for $0.3 \%$ of all hospital admissions. This is lower than the $0.6 \%-1.3 \%$ of adverse events contributing to death extrapolated in previous general GTT studies. ${ }^{34}$ This difference can be explained by large random variation when extrapolation is based on small numbers of adverse events contributing to death.

The high rate of adverse events in our study can partly be explained by the inclusion of adverse events originating in primary care, prior to admission. Patients dying in the hospital are a highly selected group of patients who are older, stay longer, are mainly emergency admissions and have a smaller range of primary diagnoses. From a previous study, we know that the risk of adverse events increases by $1.3 \%$ for every year increase in age and $5.1 \%$ for each day spent in the hospital. ${ }^{21}$ To have a representative population, we argue that measuring adverse events contributing to death should be based on inpatient deaths rather than generalisation of reviews of general hospitalised patients.

Even after adjusting rates of adverse events for demographic variables and primary diagnosis patients dying in hospitals have nearly twice the rate of adverse events per 1000 patient days. This indicates that rates of adverse events for inpatient deaths are influenced by other factors than just demographic characteristics. Many patients who die in hospitals are very ill and frail from underlying conditions, making them more vulnerable to adverse events. It is rarely straightforward to establish that an adverse event has led directly to death. More often, the adverse event is one of many factors contributing to death. This does not diminish the importance of the event, but should instead encourage us to monitor and treat these patients with utmost care and caution.

Inpatient deaths experience seven times the rate of severe adverse events than found in the general GTT sample, and much greater rates compared with any other general GTT studies. ${ }^{18-20}$ Our general sample includes $8.7 \%$ of hospitalised patients in our trust, including $8.8 \%$ of the inpatient deaths. In our general sample, we found only three adverse events so severe that they contributed to death. This difference in the rate of adverse events contributing to death could be due to differences in sample size, and the fact that adverse events contributing to death are rare in general hospitalised patients. Then again, we find no significant difference in the rate of more common temporary adverse events (severity $\mathrm{E}$ and $\mathrm{F}$ ) between the two samples. We argue that using the GTT method on a general hospitalised population is appropriate for identifying more common temporary adverse events, but the sample size is too small to provide reliable metrics of rarely occurring severe adverse events.
By including all inpatients deaths, we avoid this sampling error. Our data demonstrate that reviewing all inpatient deaths can provide new valid and reliable data of severe adverse events which otherwise would be undetected.

To evaluate the total number of adverse events resulting from medical care, we included all adverse events associated with care given prior to hospitalisation. Nearly one-third of adverse events contributing to death are present on admission and originates in primary care. These patients are on average older than other inpatient deaths and are often admitted from a nursing home. On average, they die within a week after admission and have a much shorter length of stay than patients acquiring their adverse event during hospitalisation. Our study does not investigate more deeply the circumstances around these admissions. Nevertheless, it raises questions as to whether the patient should have been admitted before or not admitted at all. Given that nearly one-third of patients are admitted with an adverse event contributing to death, it seems likely that the quality of care provided in primary care prior to admission to some degree affects the mortality measures of hospitals.

Baines et al have found that inpatient deaths have a lower proportion of surgical-related adverse events and a greater proportion of preventable hospital-acquired infections. ${ }^{5}$ In our study, we find that healthcare-associated infections, medication harm and pressure ulcers are significantly more frequent among inpatient deaths than in the general sample. We identified a greater proportion of surgically related adverse events among inpatient deaths but adjusting for demographic variables, there is no significant difference between the samples.

We find that lower respiratory infections are the most common severe adverse event, occurring nearly three times as frequently and contributing to the death of nearly half of the inpatient deaths. Pneumonia is one of the most common infections requiring hospitalisation, ${ }^{22}$ and for one-third of these patients, pneumonia originating in primary care contributed to death. The prevalence of lower respiratory infections in our study may be accounted for by the inclusion of adverse events originating in primary care. Studies over the last decade have shown that healthcare-associated pneumonia, for instance, acquired in nursing homes, differs from community-acquired pneumonia in terms of pathogens, symptoms and prognosis. ${ }^{23}{ }^{24}$ Delayed recognition of symptoms and delayed delivery of appropriate antimicrobial therapy result in excess mortality. ${ }^{25}$ These patients are older and have a greater burden of comorbidities, so patients at risk of healthcare-associated pneumonia are also those at increased risk of dying from their underlying conditions. This makes the causality of death hard to establish. Due to this, many clinicians have judged lower respiratory infections difficult to prevent. Judging preventability is a subjective process varying between reviewers, affected by culture and are changing over 
time. ${ }^{11} 26$ Healthcare-associated and hospital-acquired pneumonia are nevertheless important causes of severe adverse events that need to be considered when trying to improve patient safety. We argue that not judging preventability provides a more robust and reliable measurement of adverse events contributing to death.

Inpatient deaths have five times the risk for medication-related adverse events. Nearly all of the medication adverse events contributing to death were related to the treatment given in hospitals. More than $70 \%$ of severe medication adverse events contributing to death occur in patients with cancer, and most of these adverse events were related to lethal complications after chemotherapy. This makes medication adverse events primarily a safety issue in hospitals and confirms other studies identifying chemotherapy as a severe risk factor for adverse events in patients with cancer. ${ }^{27} 28$

\section{Strengths and limitations}

This study has the standard limitations of retrospective patient record reviewing such as information bias and poor to moderate reliability. The review process was performed in a slightly different way for the two samples. The step where the physician comes to consensus with the nurses for the inpatient death sample can have influenced what was considered an adverse event and its severity. Hindsight bias could be another limitation. Knowing the outcome and its severity on the judgement of causation could influence the judgement. ${ }^{29}$ The outcome of inpatient death is death, compared with the general sample where the outcome and the severity of the adverse events are largely unknown at the start of the review process. Hindsight bias may have led to an overestimation of the number and severity of adverse events for the inpatient death sample. To reduce the risk of hindsight bias, we added an extra step in the reviewing process of the inpatient death sample, where two independent physicians reviewed and discussed the most severe adverse events contributing to death once more before consensus was reached. The good correlation between the reviewing physicians could indicate a low effective hindsight bias, and we argue that adding this extra step increases the validity of the results for the inpatient deaths. Another strength of our study is that all inpatient deaths in our hospital trust are included, avoiding selection bias and providing a more accurate measurement of the contribution of adverse events to death in hospitalised patients.

\section{CONCLUSION}

Patients dying in hospitals differ in several ways from a general hospitalised population and experience seven times the rate of severe adverse events. GTT review of general hospitalised patients primarily identifies more common temporary adverse events, while a review of all inpatient deaths provides a new valid and reliable measurement of severe adverse events contributing to death that otherwise would be undetected. Demographic differences and sample size argue that mortality estimates of adverse events rarely contributing to death should not be extrapolated from GTT reviews of small general samples of hospitalised patients.

Acknowledgements The authors would like to thank the GTT review teams at Nordland Hospital Trust, especially Trude Merethe Kristiansen, Siv-Heidi Simonsen and Dr Ida Bakke for review contributions of inpatient deaths. They also thank Tom Wilsgaard for advice on statistical analysis, Alexander Ringdal, Elisabeth Mentzoni and Marina Mineeva for help with data processing.

Contributors $\mathrm{ECH}$ and $\mathrm{BV}$ : designed the study. ECH and KM: review and collection of data. ECH: analysed the data supervised by BV and led the writing of the paper. $\mathrm{ECH}, \mathrm{BV}, \mathrm{CvP}$ and $\mathrm{CN}$ : interpreted the data. All authors contributed revising the manuscript; contributed substantially to the writing of the paper, and reviewed and approved the final draft.

Funding ECH receives a grant from the Northern Norway Regional Health Authority (HST1195-14).

\section{Competing interests None declared.}

Ethics approval The Regional Committee of Ethics in Norway has reviewed the study and categorised it as retrospective health record research, which does not require approval by the committee (2013/1823).

Provenance and peer review Not commissioned; externally peer reviewed.

Data sharing statement № additional data are available.

Open access This is an open access article distributed in accordance with the Creative Commons Attribution Non Commercial (CC BY-NC 4.0) license, which permits others to distribute, remix, adapt, build upon this work non-commercially, and license their derivative works on different terms, provided the original work is properly cited, appropriate credit is given, any changes made indicated, and the use is non-commercial. See: http://creativecommons.org/licenses/by-nc/4.0/.

\section{REFERENCES}

1. Makary MA, Daniel M. Medical error-the third leading cause of death in the US. BMJ 2016;353:i2139.

2. James JT. A new, evidence-based estimate of patient harms associated with hospital care. J Patient Saf 2013;9:122-8.

3. Landrigan CP, Parry GJ, Bones CB, et al. Temporal trends in rates of patient harm resulting from medical care. $N$ Engl $J$ Med 2010;363:2124-34.

4. Classen DC, Resar R, Griffin F, et al. 'Global trigger tool' shows that adverse events in hospitals may be ten times greater than previously measured. Health Aff 2011;30:581-9.

5. Baines RJ, Langelaan M, de Bruijne MC, et al. Is researching adverse events in hospital deaths a good way to describe patient safety in hospitals: a retrospective patient record review study. BMJ Open 2015;5:e007380.

6. Huddleston JM, Diedrich DA, Kinsey GC, et al. Learning from every death. J Patient Saf 2014;10:6-12.

7. Zegers M, de Bruijne MC, Wagner C, et al. Adverse events and potentially preventable deaths in Dutch hospitals: results of a retrospective patient record review study. Qual Saf Health Care 2009;18:297-302.

8. Roberts AP, Morrow G, Walkley M, et al. From research to practice: results of 7300 mortality retrospective case record reviews in four acute hospitals in the North-East of England. BMJ Open Qual 2017;6:e000123.

9. Zimmerman R, Pierson S, McLean R, et al. Aiming for zero preventable deaths: using death review to improve care and reduce harm. Healthc Q 2010;13(Spec No):81-7.

10. Hogan $\mathrm{H}$, Healey $\mathrm{F}$, Neale $\mathrm{G}$, et al. Learning from preventable deaths: exploring case record reviewers' narratives using change analysis. $J$ $R$ Soc Med 2014;107:365-75.

11. Hogan H. The problem with preventable deaths. BMJ Qual Saf 2016;25:320-3.

12. Kavanagh KT, Saman DM, Bartel R, et al. Estimating hospital-related deaths due to medical error: a perspective from patient advocates. $J$ Patient Saf 2017;13:13.

13. Shojania KG, Dixon-Woods M. Estimating deaths due to medical error: the ongoing controversy and why it matters. BMJ Qual Saf 2017;26:bmjqs-2016-006144. 
14. Hibbert PD, Molloy CJ, Hooper TD, et al. The application of the Global Trigger Tool: a systematic review. Int J Qual Health Care 2016;28:640-9.

15. Norwegian Institute of Public Health; The Knowledge Centre for the Health Services. Strukturert journal undersøkelse, ved bruk av Global Trigger Tool for å identifisere og måle forekomst av skader $i$ helsetjenesten. Oslo, Norway, 2010. Structured journal review, using the GTT method to identify and measure incidence of harm in health care.

16. Griffin F, Resar R. IHI Global trigger tool for measuring adverse events. 2nd edn, 2009. IHI Innovation Series white paper. www.IHI. org.

17. Hartwig SC, Denger SD, Schneider PJ. Severity-indexed, incident report-based medication error-reporting program. Am J Hosp Pharm 1991;48:2611-6.

18. Doupi P, Svaar H, Bjørn B, et al. Use of the global trigger tool in patient safety improvement efforts: Nordic experiences. Cogn Technol Work 2015;17:45-54.

19. Deilkås ET, Risberg MB, Haugen M, et al. Exploring similarities and differences in hospital adverse event rates between Norway and Sweden using Global Trigger Tool. BMJ Open 2017;7:e012492.

20. Health Quality \& Safety Commission New-Zealand. The global trigger tool: a review of the evidence (2016 edition). Wellington, NZ, 2016. www.hqsc.govt.nz. (accessed 13 Jun 2016).
21. Haukland EC, von Plessen C, Nieder C, et al. Adverse events in hospitalised cancer patients: a comparison to a general hospital population. Acta Oncol 2017;56:1218-23.

22. Kollef MH, Morrow LE, Baughman RP, et al. Health care-associated pneumonia (HCAP): a critical appraisal to improve identification, management, and outcomes-proceedings of the HCAP Summit. Clin Infect Dis 2008;46:S296-334.

23. Attridge RT, Frei CR. Health care-associated pneumonia: an evidence-based review. Am J Med 2011;124:689-97.

24. Nair GB, Niederman MS. Nosocomial pneumonia. Crit Care Clin 2013;29:521-46.

25. Venditti M, Falcone M, Corrao S, et al. Outcomes of patients hospitalized with community-acquired, health care-associated, and hospital-acquired pneumonia. Ann Intern Med 2009;150:19-26.

26. Hogan H, Healey F, Neale G, et al. Relationship between preventable hospital deaths and other measures of safety: an exploratory study. Int J Qual Health Care 2014;26:298-307.

27. Lipczak H, Knudsen JL, Nissen A. Safety hazards in cancer care: findings using three different methods. BMJ Qual Saf 2011;20:1052-6.

28. Schwappach DL, Wernli M. Medication errors in chemotherapy: incidence, types and involvement of patients in prevention. A review of the literature. Eur J Cancer Care 2010;19:285-92.

29. Fischhoff B. Hindsight not equal to foresight: the effect of outcome knowledge on judgment under uncertainty. 1975. Qual Saf Health Care 2003;12:304-11. 